\title{
Association between cyclin D1 G870A polymorphism and cervical cancer risk: a cumulative meta-analysis involving 2,864 patients and 3,898 controls
}

Yuan-Yuan $\mathrm{Hu}^{1+}$, Rong Zheng ${ }^{2+}$, Chong Guo ${ }^{2}$ and Yu-Ming Niu ${ }^{1,3^{*}}$

\begin{abstract}
Background: Association between Cyclin D1 (CCND1) polymorphism and cervical cancer risk are conflicting with published articles. We performed a meta-analysis to investigate the association between CCND1 G870A polymorphism and cervical cancer risk.

Methods: PubMed, Embase and CNKI data were researched to conduct a meta-analysis on the associations between CCND1 G870A polymorphism and cervical cancer risk. Ten published case-control studies including 2,864 patients with cervical cancer and 3,898 controls were collected in this meta-analysis. Odds ratio (OR) with 95\% confidence interval (Cl) were applied to assess the relationship; meta-regression, sensitivity analysis and cumulative analysis were also conducted to guarantee the strength of results.
\end{abstract}

Results: Overall, no significant association between CCND1 G870A polymorphism and cervical cancer risk were found in allele contrast ( $A$ vs. G: $\mathrm{OR}=1.02,95 \% \mathrm{Cl}=0.88-1.19, P=0.76 P^{2}=74.5 \%$ ), codominant model (GA vs. GG: $\mathrm{OR}=0.98$, $95 \% \mathrm{Cl}=0.77-1.26, P=0.90 P^{2}=69.1 \%$; AA vs GG: $\mathrm{OR}=1.03,95 \% \mathrm{Cl}=0.75-1.41, P=0.85 P^{2}=75.9 \%$ ), dominant model (GA + AA vs. GG: OR=1.00,95\% Cl=0.78-1.28, $P=0.99 P^{2}=72.3 \%$ ) and recessive model (AA vs GG + GA: $\left.\mathrm{OR}=1.06,95 \% \mathrm{Cl}=0.85-1.23, P=0.62, P^{2}=70.1 \%\right)$. Similarly, in the stratified analysis by ethnicity, study design and genotyping type, no significant association detected in all genetic models either.

Conclusions: Our meta-analysis indicated that CCND1 G870A might be not the crucial risk factor for the development of cervical cancer.

Virtual Slides: The virtual slide(s) for this article can be found here: http://www.diagnosticpathology.diagnomx. eu/vs/13000_2014_168

Keywords: CCND1, Polymorphism, Cervical cancer, Meta-analysis

\section{Background}

Cervical cancer is one of the most common malignant diseases; it is the third most commonly diagnosed cancer and the fourth leading cause of cancer death in females with approximately 529,800 new cases and 275,100 deaths among females in 2008 worldwide [1].

\footnotetext{
* Correspondence: n4oneone@126.com

${ }^{\dagger}$ Equal contributors

'Department of Stomatology, Taihe Hospital, Hubei University of Medicine,

32 South Renmin Road, Shiyan 442000, China

${ }^{3}$ Clinical and Evidence-Based Medicine Center, Taihe Hospital, Hubei University of Medicine, Shiyan, P. R. China

Full list of author information is available at the end of the article
}

Cervical cancer is a multifactorial and multistep disease. Innate immune deficiency, environmental aggravation, and genetic mutation have been considered as important pathopoiesis factors. New molecular epidemical studies revealed that human papillomavirus (HPV), particularly HPV 16 and 18 infections may be the common and important factor contributing to the development of cervical cancer, which is known to cause approximately $70 \%$ of cervical cancers $[2,3]$.

Abnormal cell proliferation is an important step in cancer development. Cyclins are a family of proteins that control cell progression through the cell cycle by activating

\section{Biomed Central}

(c) 2014 Hu et al.; licensee BioMed Central Ltd. This is an Open Access article distributed under the terms of the Creative Commons Attribution License (http://creativecommons.org/licenses/by/4.0), which permits unrestricted use, distribution, and reproduction in any medium, provided the original work is properly credited. The Creative Commons Public Domain Dedication waiver (http://creativecommons.org/publicdomain/zero/1.0/) applies to the data made available in this article unless otherwise stated. 
cyclin-dependent kinase (CDK) enzymes [4]. Cyclin D1 (CCND1) is a major regulatory protein that serves a critical function in the transition from $\mathrm{G} 1$ to $\mathrm{S}$ phase by binding to CDK4 and CDK6 to promote cell cycle progression during cell division [5]. Over-expression of CCND1 will induce tumor cells to pass the G1/S checkpoint of the cell cycle. Several studies have found that amplification of CCND1 and the aberrant expression of protein are associated with cell proliferation and poor prognosis in some cancers, such as head and neck cancer [6], lung cancer [7], and breast cancer [8].

Recently, molecular epidemiologic studies have directed considerable attention toward the association between genetic mutation and cancer susceptibility. Singlenucleotide polymorphisms (SNPs) are the most common type of genetic variation among people. The change in a nucleotide may alter gene functions and may influence protein expression, which could inhibit or promote cell proliferation and increase susceptibility to cancer development. In 1995, Betticher et al. [9] reported a synonymous SNP (G870A) in the CCND1 gene. The A allele has a longer half-life than the $G$ allele and has been postulated to increase CCND1 level. Such increase promotes the proliferation of abnormal cells and the escape of these cells from apoptosis.

Catarino et al. published the first research about the association between CCND1 G870A polymorphism and cervical cancer risk in 2005 [10]. Since then, a large number of epidemiological studies have been conducted, but conclusions were inconsistent. In 2014, a recent meta-analysis was conducted by $\mathrm{Wu}$ et al., which only demonstrated that no significant association existed between CCND1 G870A polymorphism and cervical cancer risk. More detailed analysis on subgroup of study design, genotyping type and heterogeneity was not conducted [11]. We therefore performed the comprehensive meta-analysis to clarify the relationship between the CCND1 G870A polymorphism and cervical cancer risk with all published studies.

\section{Methods}

\section{Search strategy}

Three electronic databases, including Pubmed, Embase, and China National Knowledge Infrastructure (CNKI), were searched with the terms "CCND1", "Cyclin D1", "cervical cancer", and "polymorphism" for studies published from 1995 to June 2014. Additional studies were identified through manual searches of the references of original studies or review articles on the topic of interest. Only studies published in English or Chinese were included. All studies selected for our meta-analysis met the following criteria: (a) observational (case-control or prospective) studies on the association between CCND1 G870A polymorphism and cervical cancer risk, (b) sufficient published data for estimating an odds ratio (OR) and 95\% confidence interval (CI), and (c) the largest or most recent samples were selected when they overlapped with other studies.

\section{Data extraction}

Data from all included studies were extracted independently by two investigators (Niu and Zheng). The extracted data included the name of the first author, publication date, country of origin, sources of controls, racial descent of the study population (categorized as Asian, Caucasian, and Mixed), number of different genotypes, and HardyWeinberg equilibrium (HWE) in controls.

\section{Statistical analysis}

The strength of the association between CCND1 G870A polymorphism and cervical cancer was evaluated by ORs with 95\% CI, comprised with allele contrast (A vs. G), codominant model (GA vs. GG, AA vs. GG), dominant model (GA + AA vs. GG), and recessive model (AA vs. GG + GA). The HWE of the control group was assessed, and a $P$ value of less than 0.05 was considered significant disequilibrium. Stratified analyses were used to evaluate ethnicity, study design, and genotyping type technique. Heterogeneity was explored with the use of a chi-squared test, and the quantity of heterogeneity was measured by the $I^{2}$ statistic. $I^{2}$ values of $25 \%, 50 \%$, and $75 \%$ represent low, moderate, and high heterogeneity, respectively. The OR of each model was estimated by using the fixed-effects model (Mantel-Haenszel method) when $I^{2} \leq 50 \%$; otherwise, the random-effects model (DerSimonian and Laird method) was used. Meta-regression analyses were performed to assess potential covariates that can predict intertribal heterogeneity. Publication bias was assessed on the basis of modified Egger's bias test and Begg's funnel plot. Statistical analysis was performed by using STATA versions 11.0 (Stata Corporation, College Station, TX). Two-sided $P$ value $(P<0.05)$ was considered statistically significant.

\section{Results}

\section{Study characteristic}

A total of 25 possible articles were searched in Pubmed $(n=12)$, Embase $(n=9)$, and CNKI $(n=4)$ (Figure 1$)$. Nine duplicates and three irrelevant references were excluded through abstract screening. Ten published casecontrol studies involving 2,864 patients with cervical cancer and 3,898 controls met our inclusion criteria $[10,12-20]$. The data included from each study on different populations are presented in Table 1. Only two studies deviated from HWE in control populations $[13,15]$.

\section{Meta-analysis}

Overall, no significant association was found between CCND1 G870A polymorphism and cervical cancer risk 


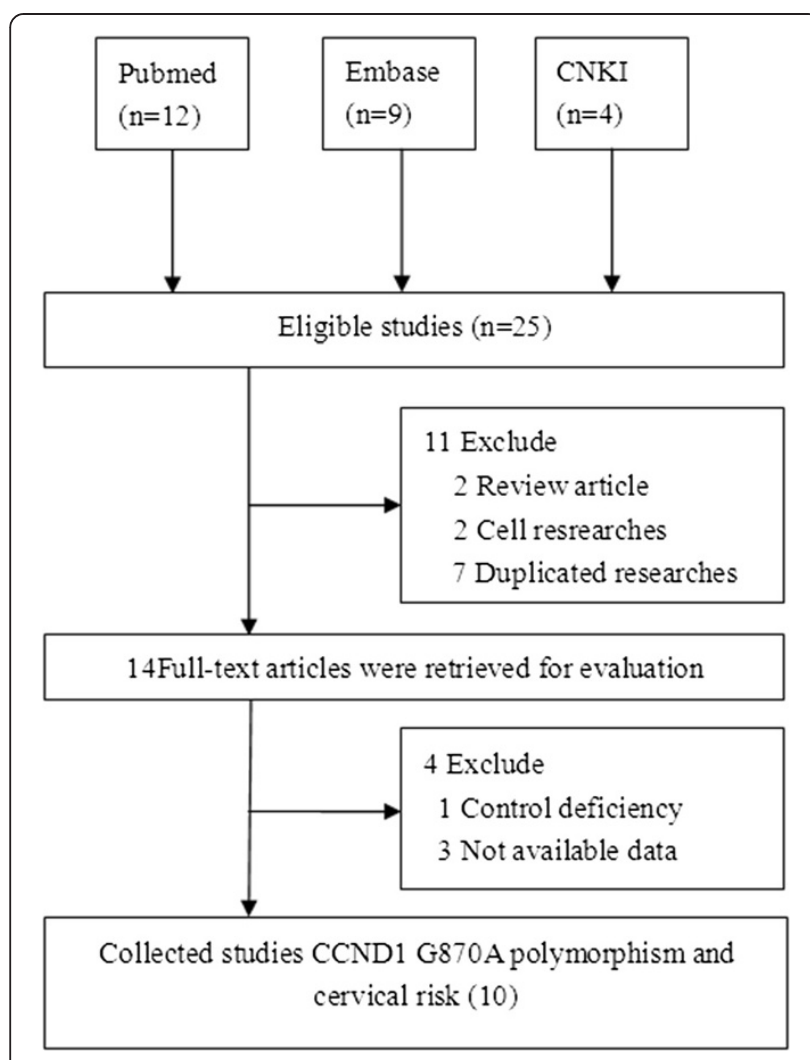

Figure 1 Flow diagram of the study selection process.

in this meta-analysis (Table 2). Values of ORs with 95\% CI were as follows: allele contrast (A vs. G: $\mathrm{OR}=1.02$, 95\% $\left.\mathrm{CI}=0.88-1.19, \quad P=0.76 I^{2}=74.5 \%\right) ;$ codominant model (GA vs. GG: $\mathrm{OR}=0.98,95 \% \mathrm{CI}=0.77-1.26, P=0.90 I^{2}=$ 69.1\%; AA vs GG: $\mathrm{OR}=1.03,95 \% \mathrm{CI}=0.75-1.41, P=0.85$
$\left.I^{2}=75.9 \%\right)$; dominant model (GA + AA vs. GG: OR $=1.00$, $95 \% \mathrm{CI}=0.78-1.28, P=0.99 I^{2}=72.3 \%$, Figure 2); and recessive model (AA vs GG + GA: OR $=1.06,95 \% \mathrm{CI}=0.85$ $1.23, P=0.62, I^{2}=70.1 \%$ ). In the succeeding analysis of HWE studies, similar associations were found. In the stratified analyses of ethnicity, study design, and genotype, no significant association was found between CCND1 G870A polymorphism and cervical risk in almost all models. Heterogeneity was observed in all five genotype models. Metaregression and stratified analyses were conducted, but no critical factors were found to explain heterogeneity in the subgroup of ethnicity, design, and genotype either (e.g., GA + AA vs. GG model: $P=0.321$ for ethnicity, $P=0.819$ for design, and $P=0.398$ for genotype).

\section{Sensitivity analysis and cumulative analysis}

Studies included in the meta-analysis were deleted one by one to reflect the influence of an individual dataset on the pooled ORs. The results were consistent (Figure 3 for the dominant model) for all of the researched genetic models, indicating that our results were statistically robust. In the cumulative meta-analysis, the result became negative form the second study of Jeon et al. [12] (Figure 4).

\section{Publication bias}

Funnel plot and Egger's test were used to estimate publication bias. The shapes of the funnel plots for all genetic models did not reveal any asymmetrical evidence. Figure 5 shows the shapes of the funnel plots of the dominant model used to examine all publications in the meta-analysis. The result was further supported by the analysis of the data with Egger's test. No significant publication bias was found in this meta-analysis $(P=0.643$

Table 1 Characteristics of case-control studies on CCND1 G870A polymorphisms and cervical cancer risk included in the meta-analysis

\begin{tabular}{|c|c|c|c|c|c|c|c|c|c|c|c|c|c|c|}
\hline \multirow[t]{3}{*}{ First author } & \multirow[t]{3}{*}{ Year } & \multirow[t]{3}{*}{ Country } & \multirow{3}{*}{$\begin{array}{l}\text { Racial/ } \\
\text { descent }\end{array}$} & \multirow{3}{*}{$\begin{array}{l}\text { Source of } \\
\text { controls }\end{array}$} & \multirow[t]{3}{*}{ Case } & \multirow[t]{3}{*}{ Control } & \multicolumn{6}{|c|}{ Genotype distribution } & \multirow{3}{*}{$\begin{array}{l}P \text { for } \\
\text { HWE }^{a}\end{array}$} & \multirow[t]{3}{*}{ Genotying type } \\
\hline & & & & & & & \multicolumn{3}{|c|}{ Case } & \multicolumn{3}{|c|}{ Control } & & \\
\hline & & & & & & & GG & $G A$ & $A A$ & GG & $G A$ & $A A$ & & \\
\hline Catarino & 2005 & Portugal & Caucasian & Healthy base & 143 & 103 & 35 & 64 & 44 & 9 & 55 & 39 & 0.091 & PCR-RFLP \\
\hline Jeon & 2005 & Korean & Asian & Hospital base & 222 & 314 & 49 & 112 & 61 & 80 & 160 & 74 & 0.730 & PCR-RFLP \\
\hline Catarino & 2008 & Portugal & Caucasian & Hospital base & 226 & 247 & 60 & 103 & 63 & 40 & 138 & 69 & 0.037 & PCR-RFLP \\
\hline Satinder & 2008 & India & Asian & Healthy base & 150 & 150 & 33 & 64 & 53 & 30 & 65 & 55 & 0.184 & PCR-RFLP \\
\hline Thakur & 2009 & India & Asian & Hospital base & 200 & 200 & 39 & 94 & 67 & 47 & 119 & 34 & 0.006 & PCR-RFLP \\
\hline Castro & 2009 & Sweden & Caucasian & Population base & 952 & 1713 & 229 & 463 & 260 & 465 & 837 & 411 & 0.367 & $\begin{array}{l}\text { Multiplex PCR and } \\
\text { hybridization }\end{array}$ \\
\hline $\mathrm{Ni}$ & 2011 & China & Asian & Hospital base & 300 & 312 & 48 & 160 & 92 & 70 & 137 & 105 & 0.051 & PCR-RFLP \\
\hline Warchoł & 2011 & Poland & Caucasian & Healthy base & 129 & 288 & 35 & 65 & 29 & 116 & 123 & 49 & 0.100 & PCR-RFLP \\
\hline Wang & 2012 & China & Asian & Population base & 327 & 411 & 86 & 180 & 61 & 92 & 203 & 116 & 0.859 & PCR-RFLP \\
\hline Djansugurova & 2013 & Kazakhstan & Caucasian & Healthy base & 215 & 160 & 54 & 103 & 58 & 41 & 78 & 41 & 0.752 & Direct sequencing \\
\hline
\end{tabular}


Table 2 Summary ORs and 95\% Cl of CCND1 G870A polymorphisms and cervical cancer risk

\begin{tabular}{|c|c|c|c|c|c|c|c|c|c|c|c|c|c|c|c|c|c|c|c|c|c|}
\hline & \multirow[b]{2}{*}{$\mathrm{N}^{*}$} & \multicolumn{4}{|c|}{ A vs. $G$} & \multicolumn{4}{|c|}{ GA vs. GG } & \multicolumn{4}{|c|}{ AA vs. GG } & \multicolumn{4}{|c|}{ GA + AA vs. GG } & \multicolumn{4}{|c|}{$A A$ vs. $G G+G A$} \\
\hline & & $\overline{\mathrm{OR}}$ & $95 \% \mathrm{Cl}$ & $P$ & $I^{2}(\%)^{a}$ & $\overline{\mathrm{OR}}$ & $95 \% \mathrm{Cl}$ & $P$ & $I^{2}(\%)^{a}$ & $\overline{O R}$ & $95 \% \mathrm{Cl}$ & $P$ & $I^{2}(\%)^{a}$ & $\overline{\text { OR }}$ & $95 \% \mathrm{Cl}$ & $P$ & $I^{2}(\%)^{a}$ & $\overline{\text { OR }}$ & $95 \% \mathrm{Cl}$ & $P$ & $1^{2}(\%)^{a}$ \\
\hline Total & 10 & 1.02 & $0.88-1.19$ & 0.76 & 74.5 & 0.98 & $0.77-1.26$ & 0.90 & 69.1 & 1.03 & $0.75-1.41$ & 0.85 & 75.9 & 1.00 & $0.78-1.28$ & 0.99 & 72.3 & 1.06 & $0.85-1.32$ & 0.62 & 70.1 \\
\hline HWE & 8 & 1.01 & $0.86-1.18$ & 0.92 & 71.9 & 1.08 & $0.85-1.39$ & 0.52 & 62.2 & 1.00 & $0.72-1.39$ & 0.99 & 73.1 & 1.06 & $0.82-1.36$ & 0.66 & 68.7 & 0.97 & $0.79-1.20$ & 0.79 & 59.8 \\
\hline \multicolumn{22}{|l|}{ Ethnicity } \\
\hline Caucasian & 5 & 0.99 & $0.79-1.25$ & 0.95 & 78.1 & 0.84 & $0.52-1.35$ & 0.47 & 82.8 & 0.92 & $0.56-1.52$ & 0.75 & 79.8 & 0.87 & $0.54-1.39$ & 0.55 & 84.5 & 1.13 & $0.97-1.30$ & 0.11 & 1.3 \\
\hline Asian & 5 & 1.05 & $0.84-1.33$ & 0.65 & 76.1 & 1.11 & $0.88-1.40$ & 0.38 & 25.6 & 1.13 & $0.70-1.83$ & 0.61 & 77.1 & 1.10 & $0.86-1.41$ & 0.44 & 40.4 & 1.06 & $0.68-1.65$ & 0.79 & 83.9 \\
\hline \multicolumn{22}{|l|}{ Design } \\
\hline Healthy base & 4 & 0.98 & $0.71-1.36$ & 0.91 & 76.8 & 0.88 & $0.47-1.64$ & 0.70 & 78.1 & 0.90 & $0.45-1.78$ & 0.76 & 77.5 & 0.89 & $0.47-1.67$ & 0.71 & 81.3 & 1.02 & $0.79-1.31$ & 0.91 & 6.7 \\
\hline Hospital base & 4 & 1.11 & $0.87-1.40$ & 0.40 & 71.7 & 0.99 & $0.60-1.63$ & 0.96 & 79.4 & 1.24 & $0.75-2.07$ & 0.40 & 74.5 & 1.06 & $0.68-1.66$ & 0.80 & 76.6 & 1.25 & $0.82-1.89$ & 0.30 & 77.1 \\
\hline Population base & 2 & 0.94 & $0.64-1.39$ & 0.76 & 91.0 & 1.08 & $0.91-1.28$ & 0.38 & 0.0 & 0.87 & $0.39-1.95$ & 0.73 & 91.2 & 1.00 & $0.70-1.44$ & 0.99 & 72.7 & 0.85 & $0.42-1.70$ & 0.64 & 92.0 \\
\hline \multicolumn{22}{|l|}{ Genotyping type } \\
\hline PCR-RFLP & 8 & 1.00 & $0.82-1.23$ & 0.97 & 78.3 & 0.94 & $0.67-1.33$ & 0.73 & 75.3 & 0.98 & $0.64-1.51$ & 0.93 & 79.6 & 0.96 & $0.68-1.34$ & 0.79 & 77.3 & 1.04 & $0.77-1.40$ & 0.80 & 74.9 \\
\hline Other & 2 & 1.12 & $1.01-1.25$ & 0.03 & 0.0 & 1.11 & $0.92-1.33$ & 0.27 & 0.0 & 1.25 & $1.02-1.54$ & 0.03 & 0.0 & 1.16 & $0.97-1.37$ & 0.10 & 0.0 & 1.17 & $0.99-1.39$ & 0.06 & 0.0 \\
\hline
\end{tabular}




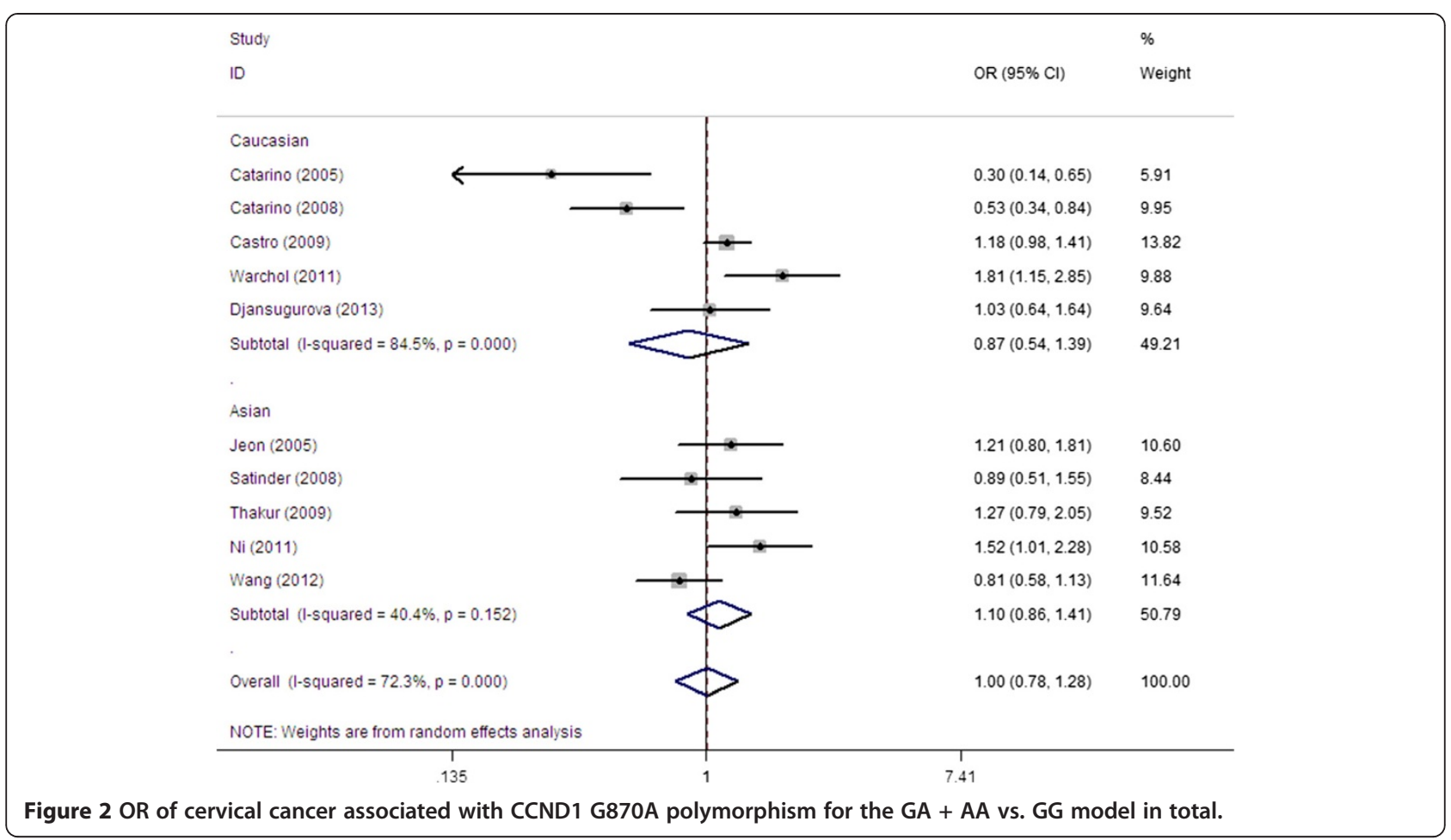

for A vs. G; GA vs. GG: $P=0.427$; AA vs. GG: $P=0.558$; $(\mathrm{GA}+\mathrm{AA})$ vs. GG: $P=0.423$; AA vs. $(\mathrm{GG}+\mathrm{GA}): P=0.884)$.

\section{Discussion}

Cervical cancer is one of the most dangerous causes of health deficiency and death worldwide. Epidemiological studies have revealed that HPV infection is an important factor contributing to cervical cancer. Furthermore, gene mutation and abnormal tumor cell proliferation may serve critical functions in cancer development.
The CCND1 gene is located at chromosome 11q13 and encodes a key cell cycle regulatory protein with 295 amino acids. CCND1 is an activator of CDK, which can regulate cell division by accelerating/decelerating the transition from G1 to S phase. Over-expression of CCND1 could result in the aberrant proliferation of DNA damage and the accumulation of genetic errors. Some SNPs of CCND1 have been reported. The G-to-A mutation is found in a well-known locus in the boundary of exon 4 and intron 4 . This mutation does not alter any amino acid in the protein

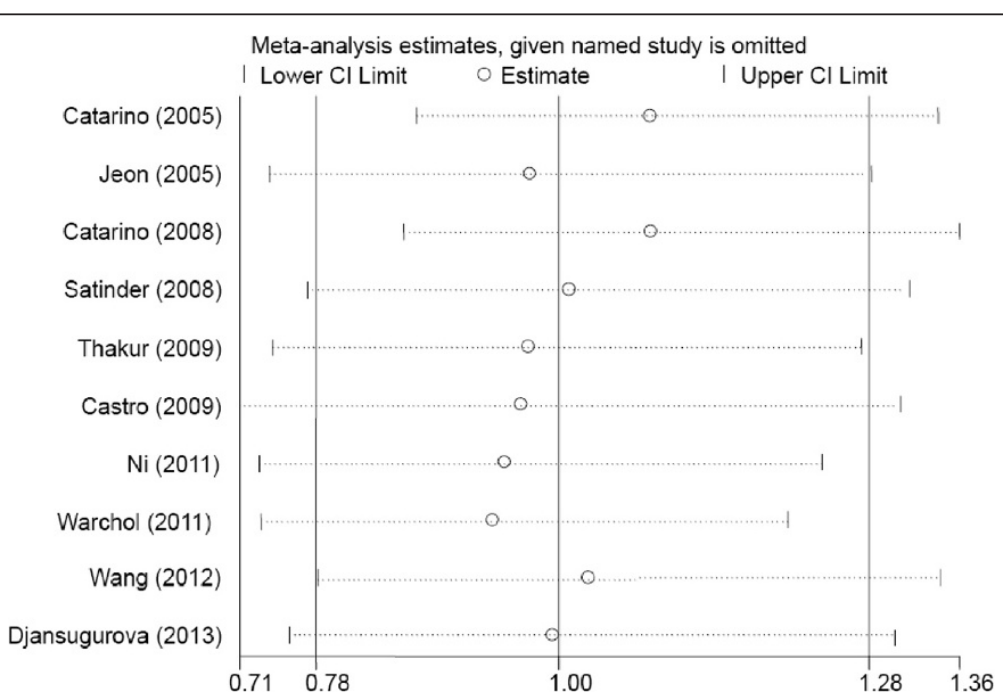

Figure 3 Sensitivity analysis through deleting each study to reflect the influence of the individual dataset to the pooled ORs in GA + AA model. 


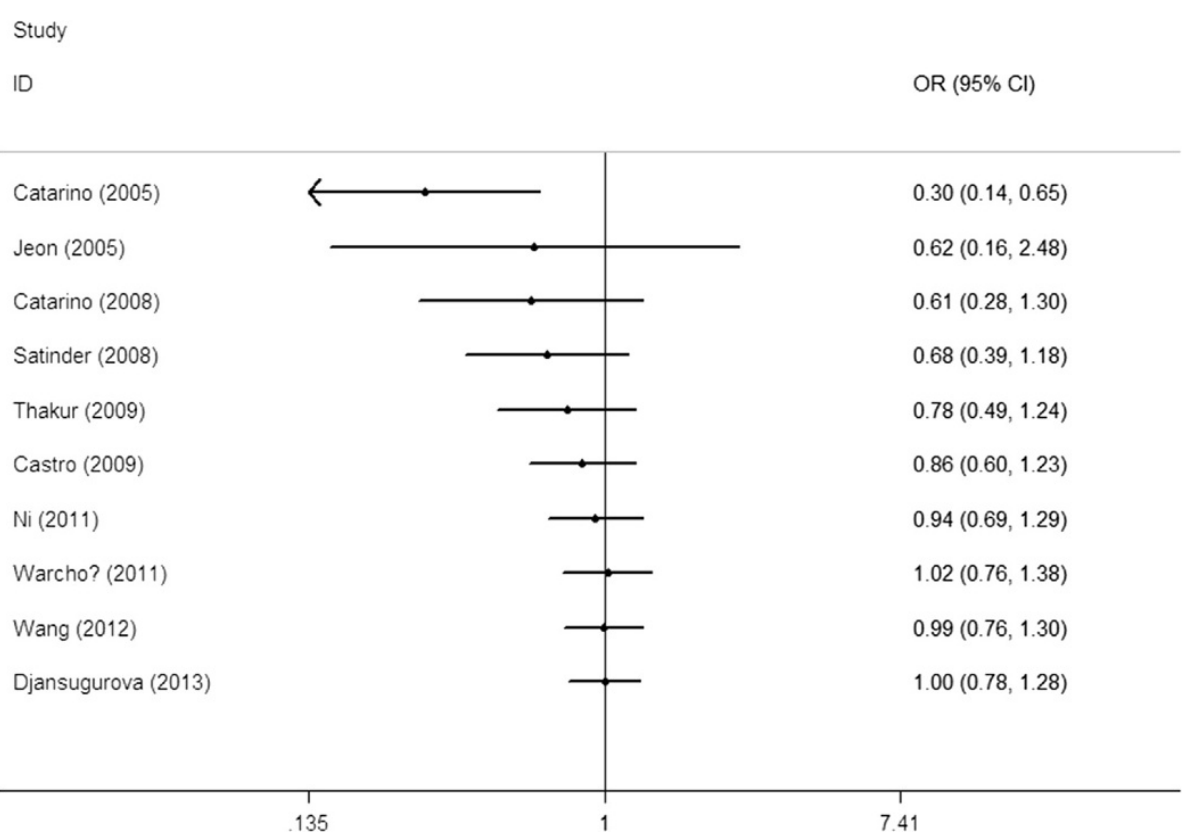

Figure 4 Cumulative meta-analyses according to publication year in GA + AA vs. GG model.

sequence. CCND1 G870A mutation results in an alternatively spliced transcript with a longer half-life than the CCND1 G allele and thus enables abnormal cells to pass through the G1-S checkpoint easily. Previous studies have demonstrated that CCND1 G870A polymorphism is significantly associated with the development of various cancers, such as breast cancer, prostate cancer, colorectal cancer, and other cancer types [21-25].

In 2005, Catarino et al. firstly find that CCND1 GG polymorphism is associated with a 3.45 -fold higher risk for the development of cervical cancer in a Portuguese population $(\mathrm{OR}=3.45,95 \% \mathrm{CI}: 1.47-7.56)$ [10]. The same results were reported in a subsequent study in 2008 [13]. Similarly, the report by Wang et al. also demonstrated that the GG/GA genotype increased the cervical cancer risk in a Chinese population $(\mathrm{OR}=3.31$, 95\% CI: 1.28-8.59) [19]. By contrast, Satinder et al. found that the AA genotype elevated cervical cancer susceptibility in Indians (OR $=3.7,95 \% \mathrm{CI}$ : $1.56-8.87)$ [14]. Thakur et al. also indicated in 2009 that Indian individuals carrying the AA genotype have a 2.49 -fold increased risk of developing cervical cancer $(\mathrm{OR}=2.49$, 95\% CI: 1.51-4.09) [15]. Moreover, other studies by Castro et al. [16] and Warchol et al. [18] found a



Figure 5 Funnel plot analysis to detect publication bias for GA + AA model. Each point represents a separate study. 
significant association between the A allele and cervical cancer risk. However, some other studies did not reveal any significant associations between CCND1 G870A polymorphism and cervical cancer.

In 2011, Ni et al. reported the first meta-analysis on the association between CCND1 G870A polymorphism and cervical cancer risk [17]. Only five studies were included in their review. The small sample size without stratified and cumulative analysis may have influenced the strength of their results. Furthermore, in the subsequent meta-analysis of $\mathrm{Wu}$ et al., the strength of the conclusion was not enough due to the lack of detailed analysis [11]. Our updated meta-analysis, which includes 10 case-control studies with 2,864 patients and 3,898 controls, did not reveal any significant associations for all genetic models even when stratified analysis was conducted according to ethnicity, study design, and genotyping type. Moreover, the interaction between G870A polymorphism, HPV infectious status and cervical cancer risk was not conducted due to the deficiency of the data. Nevertheless, some current studies have shown that the presence of HPV infection combined with CCND1 G870A polymorphism might increase the risk of cervical cancer, which was consistent with the published reports with positive expression of HPV infection in cervical cancer [19,26,27]. Large sample size with more carefully stratified analyses, more exact statistic techniques and cumulative analysis and meta-regression analysis indicated that our results were statistically robust.

Our analysis has some limitations. First, some heterogeneity still exists despite stratified analysis, and the meta-regression could not be explained successfully. Second, some environmental factors, such as smoking, drinking, and HPV infection, were not included in our meta-analysis because of data deficiency. Third, the sample size was relatively small, which might have yielded false results and inaccurate conclusions.

\section{Conclusion}

In conclusion, this meta-analysis indicated that CCND1 G870A polymorphism may not be a risk factor of cervical cancer development. Large and well-designed case-control studies are needed to validate our findings further.

\section{Consent}

Written informed consent was obtained from the patient for the publication of this report and any accompanying images.

\section{Abbreviations}

HWE: Hardy-Weinberg equilibrium; CCND1: Cyclin D1; SNP: Single nucleotide polymorphism; CNKI: China National Knowledge Infrastructure; OR: Odds ratio; Cl: Confidence interval.

\section{Competing interest}

The authors declare that they have no competing interest.

\section{Authors' contributions}

Yuan-Yuan Hu, Rong Zheng and Chong Guo performed the literature search, data extraction, and statistical analysis and drafted the manuscript. Yu-Ming Niu supervised the literature search, data extraction, analysis and reviews the manuscript. Yuan-Yuan Hu, Rong Zheng, Chong Guo and Yu-Ming Niu read and approved the final manuscript.

\section{Acknowledgement}

We gratefully acknowledged the support of the subjects who participated in this study. This study was partly supported by the Foundation of Ministry of Education of Hubei Province (D20142102) and Foundation of Taihe Hospital (2013GPY07)

\section{Author details}

'Department of Stomatology, Taihe Hospital, Hubei University of Medicine, 32 South Renmin Road, Shiyan 442000, China. ${ }^{2}$ Department of gynaecology and obstetrics, Taihe Hospital, Hubei University of Medicine, 32 South Renmin Road, Shiyan 442000, China. ${ }^{3}$ Clinical and Evidence-Based Medicine Center, Taihe Hospital, Hubei University of Medicine, Shiyan, P. R. China.

Received: 21 June 2014 Accepted: 16 August 2014

Published online: 10 September 2014

\section{References}

1. Jemal A, Bray F, Center MM, Ferlay J, Ward E, Forman D: Global cancer statistics. CA Cancer J Clin 2011, 61:69-90.

2. Garcia-Espinosa B, Nieto-Bona MP, Rueda S, Silva-Sanchez LF, PiernasMorales MC, Carro-Campos P, Cortes-Lambea L, Moro-Rodriguez E: Genotype distribution of cervical human papillomavirus DNA in women with cervical lesions in bioko, equatorial guinea. Diagn Pathol 2009, 4:31.

3. Tang SY, Li L, Li YL, Liu AY, Yu MJ, Wan YP: Distribution and location of daxx in cervical epithelial cells with high risk human papillomavirus positive. Diagn Pathol 2014, 9:1.

4. Galderisi U, Jori FP, Giordano A: Cell cycle regulation and neural differentiation. Oncogene 2003, 22:5208-5219.

5. Sherr CJ: Cancer cell cycles. Science 1996, 274:1672-1677.

6. Zhang B, Liu W, Li L, Lu J, Liu M, Sun Y, Jin D: Kai1/cd82 and cyclin d1 as biomarkers of invasion, metastasis and prognosis of laryngeal squamous cell carcinoma. Int J Clinical Exp Pathol 2013, 6:1060-1067.

7. Myong $\mathrm{NH}$ : Cyclin d1 overexpression, p16 loss, and prb inactivation play a key role in pulmonary carcinogenesis and have a prognostic implication for the long-term survival in non-small cell lung carcinoma patients. Cancer Res Treat 2008, 40:45-52.

8. Abramson VG, Troxel AB, Feldman M, Mies C, Wang $Y$, Sherman L, McNally S, Diehl A, Demichele A: Cyclin d1b in human breast carcinoma and coexpression with cyclin d1a is associated with poor outcome. Anticancer Res 2010, 30:1279-1285.

9. Betticher DC, Thatcher N, Altermatt HJ, Hoban P, Ryder WD, Heighway J: Alternate splicing produces a novel cyclin d1 transcript. Oncogene 1995, 11:1005-1011.

10. Catarino R, Matos A, Pinto D, Pereira D, Craveiro R, Vasconcelos A, Lopes C, Medeiros R: Increased risk of cervical cancer associated with cyclin d1 gene a870g polymorphism. Cancer Genet Cytogenet 2005, 160:49-54.

11. Wu Y, Fu H, Zhang H, Huang H, Chen M, Zhang L, Yang H, Qin D: Cyclin d1 (ccnd1) g870a polymorphisms and cervical cancer susceptibility: a meta-analysis based on ten case-control studies. Tumour Biol 2014, 35:6913-6918.

12. Jeon YT, Kim JW, Song JH, Park NH, Song YS, Kang SB, Lee HP: Cyclin d1 g870a polymorphism and squamous cell carcinoma of the uterine cervix in korean women. Cancer Lett 2005, 223:259-263.

13. Catarino R, Pereira D, Breda E, Coelho A, Matos A, Lopes C, Medeiros R: Oncogenic virus-associated neoplasia: a role for cyclin d1 genotypes influencing the age of onset of disease? Biochem Biophys Res Commun 2008, 370:118-122.

14. Satinder K, Chander SR, Pushpinder K, Indu G, Veena J: Cyclin d1 (g870a) polymorphism and risk of cervix cancer: a case control study in north indian population. Mol Cell Biochem 2008, 315:151-157. 
15. Thakur N, Hussain S, Kohaar I, Tabassum R, Nasare V, Tiwari P, Batra S, Bhambhani S, Das BC, Basir SF, Bharadwaj D, Bharadwaj M: Genetic variant of ccnd1: association with hpv-mediated cervical cancer in indian population. Biomarkers 2009, 14:219-225.

16. Castro FA, Haimila K, Sareneva I, Schmitt M, Lorenzo J, Kunkel N, Kumar R, Forsti A, Kjellberg L, Hallmans G, Lehtinen M, Hemminki K, Pawlita M: Association of hla-drb1, interleukin-6 and cyclin d1 polymorphisms with cervical cancer in the swedish population-a candidate gene approach. Int J Cancer 2009, 125:1851-1858.

17. Ni J, Wang M, Fu S, Zhou D, Zhang Z, Han S: Ccnd1 g870a polymorphism and cervical cancer risk: a case-control study and meta-analysis. J Cancer Res Clin Oncol 2011, 137:489-494.

18. Warchol T, Kruszyna L, Lianeri M, Roszak A, Jagodzinski PP: Distribution of ccnd1 a870g polymorphism in patients with advanced uterine cervical carcinoma. Pathol Oncol Res 2011, 17:133-137.

19. Wang N, Qian X, Wang S, Gao H, Wang L, Huo Y, Zhang S: Ccnd1 rs9344 polymorphisms are associated with the genetic susceptibility to cervical cancer in chinese population. Mol Carcinog 2012, 51:196-205.

20. Djansugurova LB, Perfilyeva AV, Zhunusova GS, Djantaeva KB, Iksan OA, Khussainova EM: The determination of genetic markers of age-related cancer pathologies in populations from kazakhstan. Front Genet 2013, 4:70.

21. Comstock CE, Augello MA, Benito RP, Karch J, Tran TH, Utama FE, Tindall EA, Wang Y, Burd CJ, Groh EM, Hoang HN, Giles GG, Severi G, Hayes VM, Henderson BE, Le Marchand L, Kolonel LN, Haiman CA, Baffa R, Gomella LG, Knudsen ES, Rui H, Henshall SM, Sutherland RL, Knudsen KE: Cyclin d1 splice variants: polymorphism, risk, and isoform-specific regulation in prostate cancer. Clin Cancer Res 2009, 15:5338-5349.

22. Yaylim-Eraltan I, Arikan S, Yildiz Y, Cacina C, Ergen HA, Tuna G, Gormus U, Zeybek $\mathrm{U}$, Isbir T: The influence of cyclin d1 a870g polymorphism on colorectal cancer risk and prognosis in a turkish population. Anticancer Res 2010, 30:2875-2880.

23. Sergentanis TN, Economopoulos KP: Cyclin d1 g870a polymorphism and breast cancer risk: a meta-analysis comprising 9,911 cases and 11,171 controls. Mol Biol Rep 2011, 38:4955-4963.

24. Tsai MH, Tsai CW, Tsou YA, Hua CH, Hsu CF, Bau DT: Significant association of cyclin d1 single nucleotide polymorphisms with oral cancer in Taiwan. Anticancer Res 2011, 31:227-231.

25. Akkiz H, Bayram S, Bekar A, Akgollu E, Ozdil B: Cyclin d1 g870a polymorphism is associated with an increased risk of hepatocellular carcinoma in the turkish population: case-control study. Cancer Epidemiol 2010, 34:298-302.

26. Shen $S N$, Wang $L F$, Jia $Y F$, Hao YQ, Zhang $L$, Wang H: Upregulation of microrna-224 is associated with aggressive progression and poor prognosis in human cervical cancer. Diagn Pathol 2013, 8:69.

27. Habbous S, Pang V, Eng L, Xu W, Kurtz G, Liu FF, Mackay H, Amir E, Liu G: P53 arg72pro polymorphism, hpv status and initiation, progression, and development of cervical cancer: a systematic review and meta-analysis. Clin Cancer Res 2012, 18:6407-6415.

doi:10.1186/s13000-014-0168-x

Cite this article as: Hu et al:: Association between cyclin D1 G870A polymorphism and cervical cancer risk: a cumulative meta-analysis involving 2,864 patients and 3,898 controls. Diagnostic Pathology 2014 9:168.

\section{Submit your next manuscript to BioMed Central and take full advantage of:}

- Convenient online submission

- Thorough peer review

- No space constraints or color figure charges

- Immediate publication on acceptance

- Inclusion in PubMed, CAS, Scopus and Google Scholar

- Research which is freely available for redistribution 